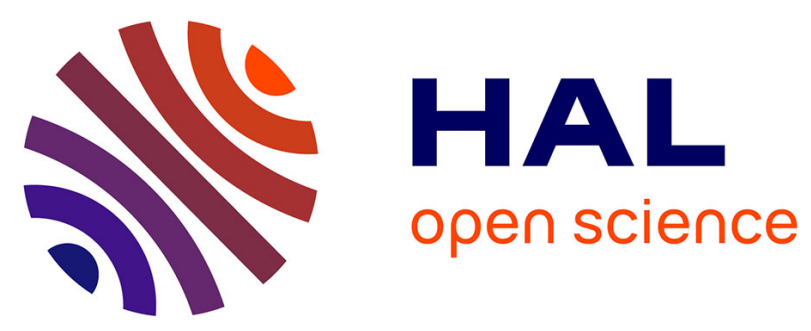

\title{
Microlenses fabricated by ultraviolet excimer laser irradiation of poly(methyl methacrylate) followed by styrene diffusion
}

Sylvain Lazare, John Lopez, Jean-Marie Turlet, Maria Kufner, Stefan Kufner, Pierre Chavel

\section{To cite this version:}

Sylvain Lazare, John Lopez, Jean-Marie Turlet, Maria Kufner, Stefan Kufner, et al.. Microlenses fabricated by ultraviolet excimer laser irradiation of poly(methyl methacrylate) followed by styrene diffusion. Applied optics, 1996, 35 (22), pp.4471-4475. 10.1364/AO.35.004471 . hal-00877695

\section{HAL Id: hal-00877695 \\ https://hal-iogs.archives-ouvertes.fr/hal-00877695}

Submitted on 29 Oct 2013

HAL is a multi-disciplinary open access archive for the deposit and dissemination of scientific research documents, whether they are published or not. The documents may come from teaching and research institutions in France or abroad, or from public or private research centers.
L'archive ouverte pluridisciplinaire HAL, est destinée au dépôt et à la diffusion de documents scientifiques de niveau recherche, publiés ou non, émanant des établissements d'enseignement et de recherche français ou étrangers, des laboratoires publics ou privés. 


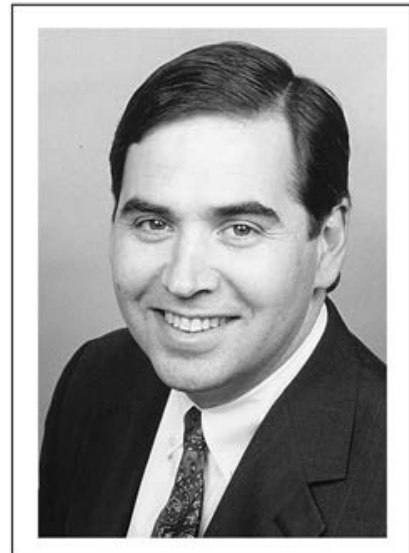

OPTICAL ACTIVITIES IN INDUSTRY

Stephen D. Fantone

Optical Activities in Industry is reported by Stephen D. Fantone, Optikos Corporation, 286 Cardinal Medeiros Avenue, Cambridge, Massachusetts 02141. Stephen welcomes letters, news, and comments for this column, which should be sent to him at the above address. sdf@world.std.com

\title{
Microlenses fabricated by ultraviolet excimer laser irradiation of poly(methyl methacrylate) followed by styrene diffusion
}

\author{
Sylvain Lazare, John Lopez, Jean-Marie Turlet, Maria Kufner, Stefan Kufner, and \\ Pierre Chavel
}

\begin{abstract}
A new technique of microlens array fabrication based on the use of excimer laser radiation is described. Poly(methyl methacrylate) (PMMA) substrates are treated with many low-energy KrF laser pulses and exposed to styrene vapor. The irradiated material swells, producing spherical microlenses that are stabilized by UV polymerization. The chemistry of this process and the optical quality of the lenses are discussed. (C) 1996 Optical Society of America

Key words: Microlens array, excimer laser radiation, PMMA, styrene diffusion.
\end{abstract}

\section{Introduction}

Miniaturization of optical setups has a need for miniaturized lenses. For several years many research

S. Lazare and J. Lopez are with the Laboratoire de Photochemie et Photophysique Moléculaire, Unité de Recherche Associée 348 du Centre National de la Recherche Scientifique, Bordeaux I, 351 cours de la Libération, F-33405 Talance, France. J.-M. Turlet is with Centre de Physique Moleculaire Optique et Hertzienne, Unité de Recherche Associée 283 du Centre National de la Recherche Scientifique, Bordeaux I, 351 cours de la Libération, F-33405 Talance, France. M. Kufner and S. Kufner are with the Vrije Universiteit Brussel, Laboratory for Phontonic Computing and Perception, Department of Applied Physics (TW-TONA), Pleinlaan 2, 1050 Brussel, Belgium. Pierre Chavel is with the Institute d'optique theorique et appliquée, Unité de Recherche Associée 14 du Centre National de la Recherche Scientifique, Université Paris Sud, BP 147, 911403 Orsay, France. groups all over the world have investigated new fabrication methods for microlenses such as ion diffusion in glass, ${ }^{1}$ photosensibilization of glass, ${ }^{2}$ melting of photoresist, ${ }^{3}$ diffractive techniques, ${ }^{4}$ excimer laser ablation and melting, ${ }^{5}$ and proton irradiation of poly(methyl methacrylate) (PMMA). ${ }^{6}$ In Ref. 6 a fabrication method for microlenses in PMMA is described that uses deep proton irradiation and subsequent styrene vapor diffusion. Because PMMA acts as a positive resist not only for proton irradiation but for any kind of radiation such as synchrotron, electron, and deep UV irradiation, this method is trans-

Received 15 November 1995; revised manuscript received 12 February 1996.

0003-6935/96/224471-05\$10.00/0

(C) 1996 Optical Society of America 


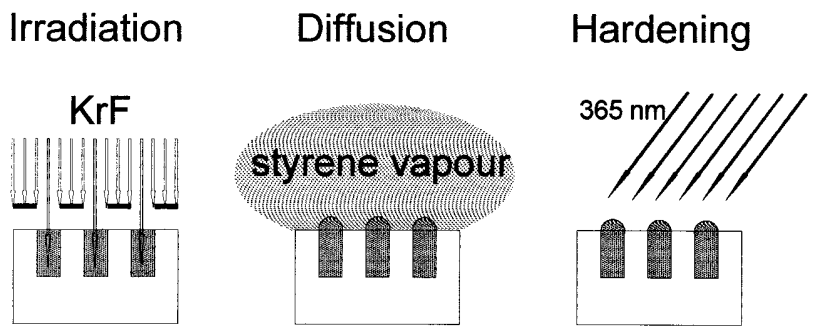

Fig. 1. Fabrication process: (a) $\mathrm{KrF}$ excimer laser $(248 \mathrm{~nm})$ irradiation of PMMA, (b) styrene diffusion, (c) mercury lamp (365 $\mathrm{nm})$ copolymerization.

ferable to these sources. ${ }^{7}$ Recently it has been shown that the lens fabrication is also possible by synchrotron irradiation ${ }^{8}$ and excimer laser irradiation. ${ }^{9}$ This paper discusses the potential of UV irradiation; an excimer laser with a 248-nm wavelength is used as a radiation source. We demonstrate that, with a convenient UV source, microlenses with interesting numerical apertures are easily obtained. This process does not require putting the sample into a vacuum environment, and it uses commercially available chromium masks on quartz. The advantage of using a UV laser is that it provides a collimated beam that is patterned by a mask that is in direct contact with the substrate. Modern excimer lasers can provide large homogeneous beams (as large as $10 \times 10 \mathrm{~cm}^{2}$ ) for large-scale fabrication.

\section{Fabrication Process}

The fabrication process is somewhat similar to the proton irradiation procedure of Ref. 6 (Fig. 1). The proton source is replaced by an excimer laser, and the mask is adapted to the radiation source. A chromium mask containing circular apertures on quartz is put on top of the PMMA plate (thickness of the order of $500 \mu \mathrm{m})$. The aperture diameter determines the final lens diameter, typically between 20 and $1000 \mu \mathrm{m}$. The irradiation is performed in air under normal incidence with pulses of a $\mathrm{KrF}$ laser $(\lambda)$ of low energy $\left(10 \mathrm{~mJ} / \mathrm{cm}^{2}\right.$, pulse duration $\left.25 \mathrm{~ns}\right)$ so that ablation does not occur (ablation threshold is $\sim 100 \mathrm{~mJ} / \mathrm{cm}^{2}$ ). The total number of pulses varied between 8000 and 30,000. As mentioned above, PMMA acts as a positive resist: that is, by irradiation its molecular weight can be decreased in domains defined laterally by the shape of the mask, and in depth its molecular weight can be decreased by the penetration of the UV photon. Once the irradiation is done the sample is placed into a hot monomer vapor atmosphere, typically with a temperature of $90{ }^{\circ} \mathrm{C}$ and a diffusion time of $45 \mathrm{~min}$. The diffusion of monomer vapor causes the irradiated domains to swell, and surface tension causes lenslike shapes to appear on top of the irradiated areas. To fix the styrene in the PMMA matrix the whole sample is illuminated with UV light of 365-nm wavelength during $30 \mathrm{~min}$ at a flux of $10 \mathrm{~mW} / \mathrm{cm}^{2}$, initiating a copolymerization process that hardens the lenses.

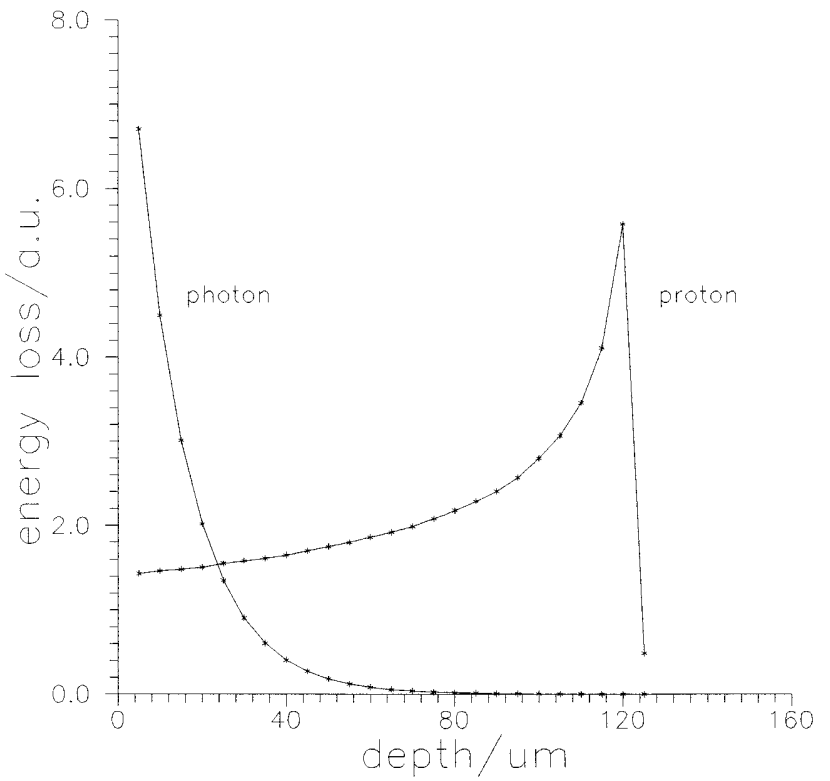

Fig. 2. Energy loss versus depth in PMMA for photon and proton irradiation.

The initiation of polymerization occurs mostly by styrene excitation because absorption of polystyrene is lower at $365 \mathrm{~nm}$. Although there are similarities between proton-beam and UV photon-beam irradiation, they yield basically different energy-depth modification profiles (Fig. 2). For proton irradiation the dose deposition curve has a sharp maximum that is well below the surface and that can be conveniently adjusted with the proton energy in a typical range as high as $1 \mathrm{~mm}$. UV photon absorption that is governed by Beer-Lambert's law gives exponential profiles if a constant absorption coefficient is assumed. However, during laser irradiation, incubation of the irradiated surface changes the absorptivity so that the profile is slightly modified. This profile modification can be studied with spectroscopic techniques presented below.

\section{Structural Characterization}

To understand the optical performance of the lenses a number of structural properties have been measured. With confocal micro-Raman spectroscopy (CMRS) the depth of modification and the styrene distribution inside the PMMA has been determined. A Jobin-Yvon-Raman spectrograph Model T64000 was used. It has the capability of recording the Raman spectrum of $1 \mu \mathrm{m}^{3}$ that is defined by the focus of the Ar+ Raman laser (448 nm). This probed volume can be adjusted to a maximum depth of $300 \mu \mathrm{m}$, which is the focal length of the microscope objective. By this technique a single irradiated volume in the PMMA can be analyzed with a high spatial resolution. Figure 3 displays the Raman spectra of irradiated and nonirradiated PMMA. The various peaks can be attributed to bond vibrations. The irradiation yields a new type of vibration at approximately $1630 \mathrm{~cm}^{-1}$ that is caused by $\mathrm{C}=\mathrm{C}$ double- 

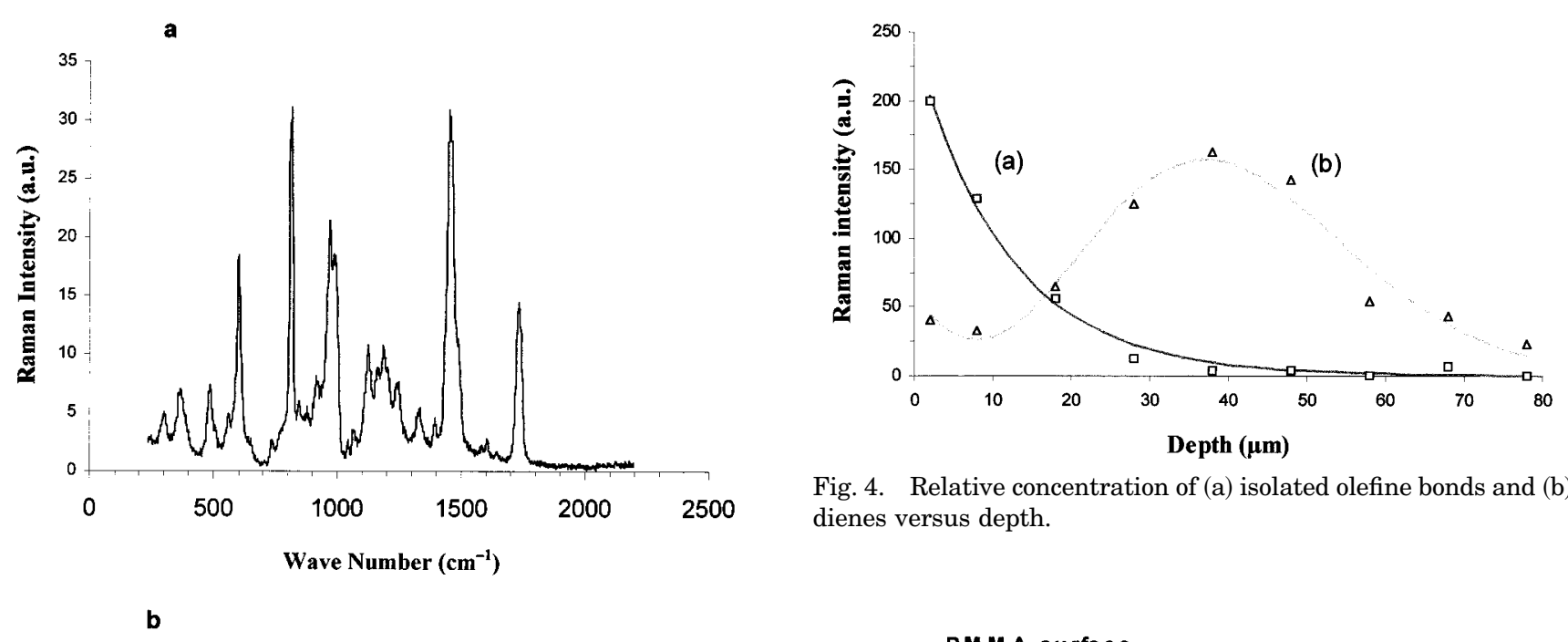

Fig. 4. Relative concentration of (a) isolated olefine bonds and (b) dienes versus depth.

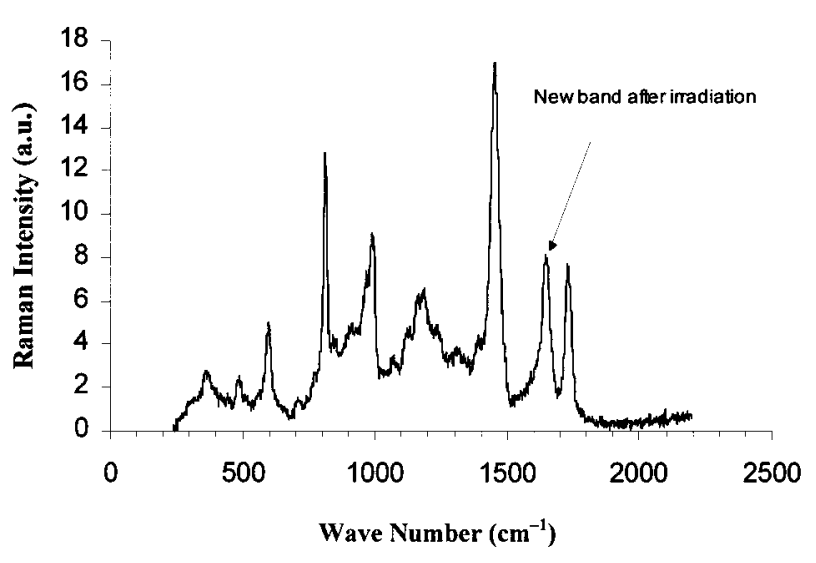

Fig. 3. Confocal micro-Raman spectrum of PMMA: a, virgin PMMA; b, after 16,000 pulses at $10 \mathrm{~mJ} / \mathrm{cm}^{2}$ and $20 \mathrm{~Hz}$.

bond (DB) elongation vibration. This new band exists up to a depth of about $100 \mu \mathrm{m}$ and can be considered as the maximum penetration depth of the 248-nm radiation in our experimental conditions (fluence, frequency). Note that the penetration depth could be extended only by use of a longer wavelength, for instance, $265 \mathrm{~nm}$ (fourth harmonic of a Nd:YAG laser). By finer analysis this peak was deconvoluted into two main components at 1646 and $1620 \mathrm{~cm}^{-1}$ and attributed to the $\mathrm{C}=\mathrm{C} \mathrm{DB}$ and $\mathrm{C}=\mathrm{C}-\mathrm{C}=\mathrm{C}$ conjugated DB's, respectively. As seen in Fig. 4, these two components display interestingly different depth profiles. It can be assumed that conjugated DB's first appear during the irradiation and then are split into DB's. The study of this modification is important because it influences the diffusion of the styrene vapor into the PMMA matrix as seen in Fig. 5. With similar CMRS measurements the styrene concentration in the microlens volume is determined. Figure 5 shows the concentration profile for irradiated and nonirradiated PMMA. As seen in the figure, diffusion takes place in both cases but not to the same extent. Diffusion is much faster in the irradiated volume, and this causes the swelling necessary for the lens formation. Unexpectedly, the concentra-

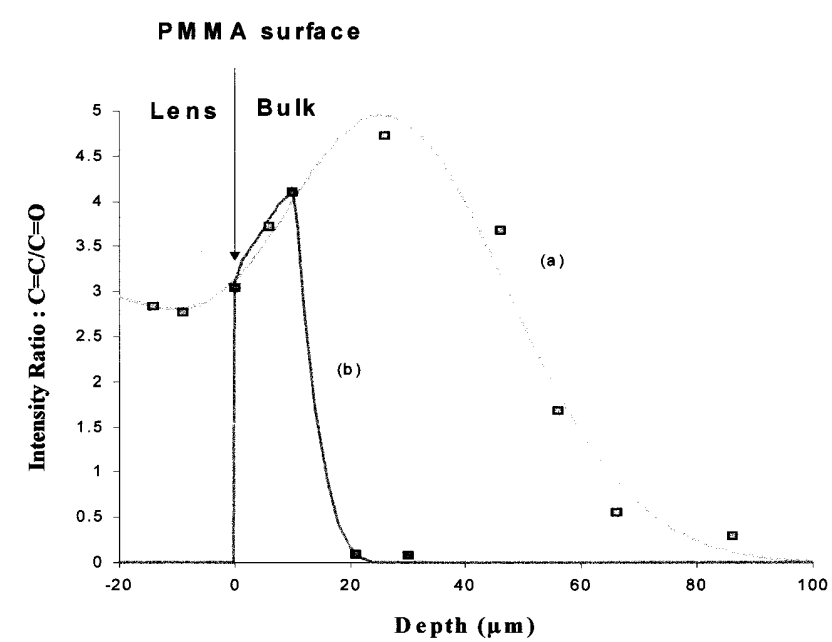

Fig. 5. Relative concentration of styrene as a function of depth (a) inside and (b) outside a lens. Negative value of depth corresponds to the swollen part of the lens above the PMMA surface. Raman intensity has been referenced to a constant peak corresponding to the $\mathrm{CO}$ vibration at $1720 \mathrm{~cm}^{-1}$.

tion of styrene on the top surface of the lens is lower than the concentration $40 \mu \mathrm{m}$ below. This is probably due to the outdiffusion of styrene that occurs early in the hardening process. This drawback may also influence the optical properties of the lenses and could be overcome by optimizing the subsequent hardening procedure. It is observed that the maximum depth of diffusion of styrene in Fig. 5 matches exactly the maximum depth of modification in Fig. 4. In fact this may be fortuitous because this depth may depend also on the styrene-vapor-exposure time that was empirically adjusted to $45 \mathrm{~min}$. Longer exposure times may give greater depth but destroy the surface tension of the lens. Homogeniety of lens volume is of particular concern, but despite the high resolution of the CMRS we did not observe any impurities of repolymerization. A relevant experimental parameter is the total dose delivered to the irradiated volume because it has a strong influence on the lens power. As can be seen in Fig. 6, the sag of the lenses increases with the dose up to a certain 


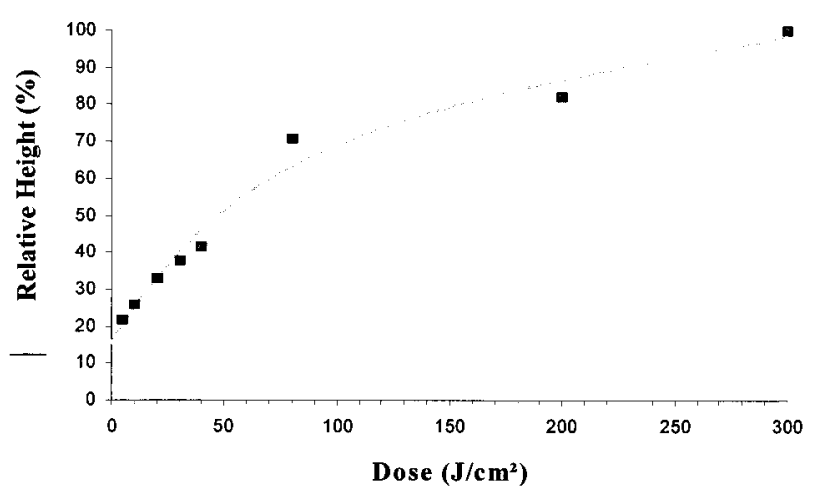

Fig. 6. Relative height of microlenses versus dose at $248 \mathrm{~nm}, 10$ $\mathrm{mJ} / \mathrm{cm}^{2}$, and $20 \mathrm{~Hz} .100 \%=10.6 \mu \mathrm{m}$.

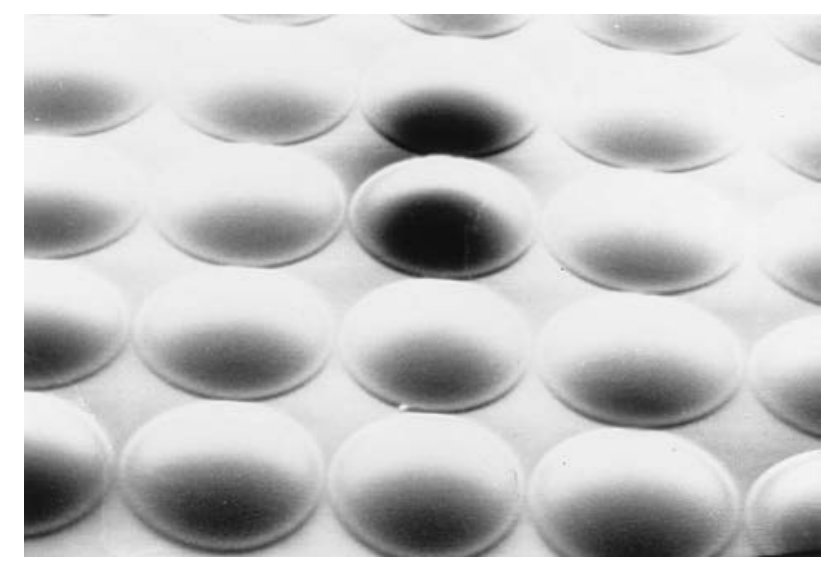

Fig. 7. Scanning electron microscope picture of a typical microlens array.

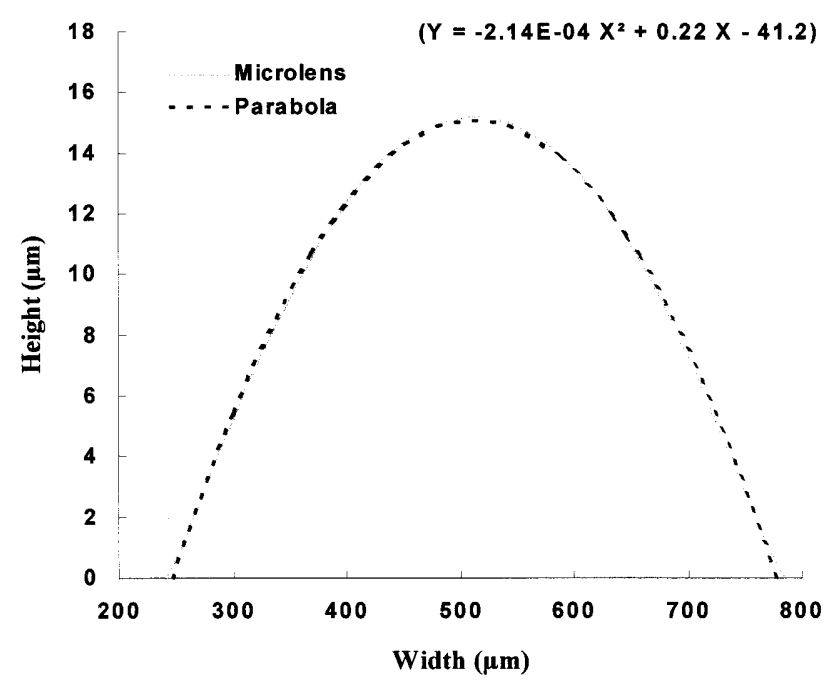

Fig. 8. Cross-sectional profile of a microlens measured with a Tencor stylus profilometer. The solid curve denotes the actual data, and the dotted curve is the theoretical parabolic fit.

saturation. At this state of research the maximum sag was $\sim 30 \mu \mathrm{m}$ even for a lens with a diameter of 1 $\mathrm{mm}$. Also, higher relative apertures may be expected when the parameters of the process and the starting material are optimized.

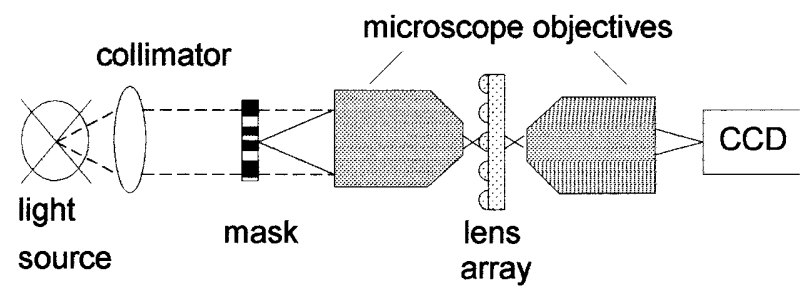

Fig. 9. Imaging setup for testing microlenses.

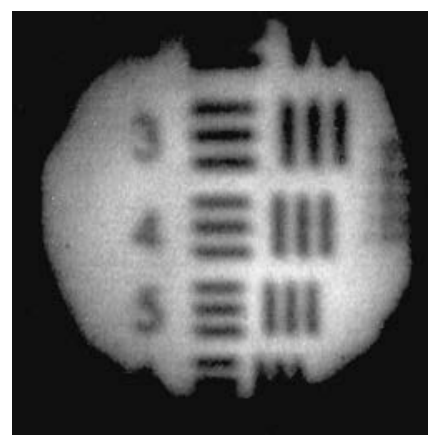

Fig. 10. Imaging experiment with a spatial frequency of 100 line pairs/mm (left half of the photograph).

\section{Optical Testing}

A typical microlens array with a lens diameter of 200 $\mu \mathrm{m}$ is shown in Fig. 7. Microscopy does not reveal any defect on the surface of the lenses. A profile has been measured with a Tencor stylus profilometer (Fig. 8). The solid curve represents the actual profilometer data, and the dotted curve is a parabolic best fit for a lens with the same base diameter and height as the real lens. The measured profile tends to approach the theoretical curve. We further investigated the imaging properties of this kind of microlens by using the setup of Fig. 9. A mask is reduced by a factor of 20 by a microscope objective. The real image seen by a microlens in a $2 f, 2 f$ arrangement is transfered to the CCD camera by a second microscope objective $(4 \times)$. The bar pattern frequency that can be resolved is better than 100 line pairs/mm (Fig. 10). The focal length in this experiment was $1 \mathrm{~mm}$, and the lens diameter was $200 \mu \mathrm{m}$. Typical $f$-numbers range from 5 to 12 .

\section{Conclusion}

It has been demonstrated that the fabrication of microlens arrays in PMMA by UV laser irradiation and subsequent styrene diffusion is possible. With this technique commercially fabricated, chromium masks on quartz that are directly in contact with the sample can be used without a need for vacuum conditions. Very large microlens arrays of several square centimeters are envisageable with a fabrication time of less than $1 \mathrm{~h}$. Structural studies have shown the good quality of the final lenses, which have a nearly spherical shape. Microscopic investigation reveals that the lens material is composed of a mixture of polystyrene and PMMA, which appears quite homogeneous for the required optical properties. The ob- 
tained lens arrays can be the template for the fabrication of a metallic master for further duplication with other moldable materials.

Parts of this work were supported by the Human Capital and Mobility Program; Ultimatech (Centre National de la Recherche Scientifique), grant IUAP24, Optoelectronic Information Technology, and grant IUAP47, Nonlinear Optics; and NFWO, Concerted Research Action, Photonics in Computing.

\section{References}

1. M. Oikawa, K. Iga, T. Sanada, N. Yamamoto, and K. Nishizawa, "Array of distributed index planar microlenses prepared from ion exchange technique," Jpn. J. Appl. Phys. 20, L296-L298 (1981).

2. N. F. Borelli, D. L. Morse, R. H. Bellmann, and W. L. Morgan, "Photolytic technique for producing microlenses in photosensitive glass," Appl. Opt. 24, 2520-2525 (1985).

3. M. C. Hutley, "Optical techniques for generation of microlens array,” J. Mod. Opt. 37, 253-265 (1990).
4. J. Jahns and S. J. Walker, "Two-dimensional array of diffractive microlenses fabricated by thin film deposition," Appl. Opt. 29, 931-936 (1988).

5. S. Mihailov and S. Lazare, "Fabrication of refractive microlens arrays by excimer laser ablation of amorphous Teflon," Appl. Opt. 32, 6211-6218 (1993).

6. M. Kufner, S. Kufner, M. Frank, J. Moisel, and M. Testorf, "Microlenses in PMMA with high relative aperture: a parameter study," Pure Appl. Opt. 2, 9-19 (1993).

7. J. O. Choi, J. A. Moore, J. C. Corelli, J. P. Silverman, and H. Bakhru, "Degradation of poly(methylmethacrylate) by deep ultraviolet, x-ray, electron beam and proton beam irradiating," J. Vac. Sci. Technol. B 6(6), 2286-2289 (1988).

8. A. Fritz, "Herstellung von mikrolinsen aus PMMA durch belichtung mit synchrotronstrahlung und styrol-diffusion und ihre charakterisierung," Master's thesis (Universität Karlsruhe, Karlsruhe, Germany, 1994).

9. M. Kufner, S. Kufner, S. Lazare, P. Pichon, and P. Chavel, "Microlenses in PMMA fabricated by particle or electromagnetic irradiation and monomer diffusion," in Microlens Arrays, Vol. 3 (Institute of Physics, London, 1995), pp. 5-8. 